\title{
A thermodynamic platform for evaluating the energy efficiency of combined power generation and desalination plants
}

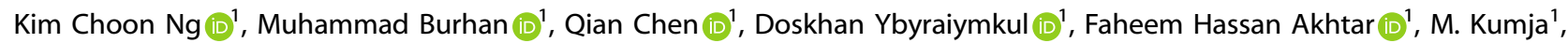 \\ Robert W. Field iD $^{2}$ and Muhammad Wakil Shahzad (iD ${ }^{2 \otimes}$
}

In seawater desalination, the energy efficiency of practical processes is expressed in $k$ Wh_electricity or low-grade-heat per $\mathrm{m}^{3}$ of water produced, omitting the embedded energy quality underlying their generation processes. To avoid thermodynamic misconceptions, it is important to recognize both quality and quantity of energy consumed. An unmerited quantitative apportionment can result in inferior deployment of desalination methods. This article clarifies misapprehensions regarding seeming parity between electricity and thermal sources that are sequentially cogenerated in power plants. These processes are represented by heat engines to yield the respective maximum (Carnot) work potentials. Equivalent work from these engines are normalized individually to give a corresponding standard primary energy $\left(Q_{\mathrm{SPE}}\right)$, defined via a common energy platform between the adiabatic flame temperature of fuel and the surroundings. Using the $Q_{S P E}$ platform, the energy efficiency of 60 desalination plants of assorted types, available from literature, are compared retrospectively and with respect to Thermodynamic Limit.

npj Clean Water (2021)4:25; https://doi.org/10.1038/s41545-021-00114-5

\section{INTRODUCTION}

Recent reports of stark gaps between the demand and supply of potable water ${ }^{1-4}$ could inhibit the aspiration for sustainable economic growth. One of the practical solutions for supplying more potable water to water stressed countries is desalination ${ }^{5-7}$. However, the energy efficiency of existing seawater desalination processes was relatively low, achieving $<16 \%$ of the thermodynamic limit $(\mathrm{TL})^{8}$. Other similar cycles or heat-driven engines have achieved higher energy efficiency levels, up to $62 \%$ of their respective ideal limits ${ }^{9-11}$. For typical seawater at ambient temperature and $3.5 \%$ concentration by weight of dissolved salts, the universal thermodynamic limit $(\mathrm{TL})$ to separate water from the solution (but at zero recovery) is $0.78 \mathrm{kWh}$ per cubic meter, as given by the Gibbs equations ${ }^{12,13}$. However, the practical specific energy consumption for seawater desalination plants available hitherto may vary from 5- to 8-folds higher than the ideal limit. As an alternative ideal limit has been reported for open systems with finite water recovery ratio, the concept of an "endoreversible thermodynamic limit" is introduced. The widely accepted cycle efficiencies for work and heat-driven desalination processes have always been defined as the ratio of useful output to the primary energy input. In this regard, the thermodynamic limit (TL) for seawater desalination can equally be understood in an orthodox manner, i.e., instead of " $X$ " $\mathrm{kWh} / \mathrm{m}^{3}$ to its reciprocal form of " $1 / X^{\prime \prime}$ $\mathrm{m}^{3} / \mathrm{kWh}$.

In the desalination industry, all secondary or derived energy are expressed by the quantitative units of kWh of electricity or thermal heat input, whilst the other aspect of energy such as quality has been unintentionally ignored, causing a likely misconception in the energy efficiency evaluation ${ }^{14,15}$. The importance of energy quality can be graphically demonstrated with three simple ideal heat engines as shown in Fig. $1(\mathrm{a}-\mathrm{c})$. Each engine is bounded by a higher and lower temperature reservoirs, i.e., $T_{\mathrm{H}}$ and $T_{\mathrm{L}}$ respectively. The isotherms are assumed to be process-average isotherms given by $T_{\text {PAT }}=\frac{\int_{\text {in }}^{\text {out }} d Q}{\int_{\text {in }}^{\text {out }}\left(\frac{\mathrm{d} Q}{T}\right)} 16,17$ and for convenience, the subscript "PAT" is dropped from all temperature reservoirs described herein. Despite the same amount of heat input (say $1 \mathrm{kWh}$ ) to all engines, the available cyclic work differs significantly and decreases with a reduction in the temperature of the heat source. It is noted that the quantity and quality of heat input $\left(Q_{H}\right)$ to an engine, operating at assorted designed temperature levels, can only be accounted for thermodynamically by standardizing it (via the Carnot work potential) to the common temperature platform to yield its equivalent $Q_{\text {SPE. }}$

Additionally, two prerequisites are needed for a fair evaluation of energy efficiency across diverse desalination processes. Firstly, all maximum or Carnot work $\left(W_{C}\right)$ of desalination cycles at their respective temperature reservoirs need standardization using a common temperature platform for the corresponding standard

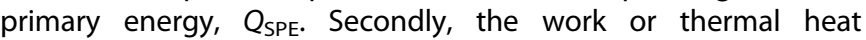
consumed by actual desalination processes, $W_{\mathrm{a}}$ or $Q_{\mathrm{th}}$ is thermodynamically linked to the Carnot work by a Second Law efficiency $\left(\eta^{\prime \prime}\right)$, defined as the ratio of the actual to Carnot work in a work-driven process or its inverse for a reverse heat engine cycle.

Although there is a plethora of exergy-based publications in literature ${ }^{18-24}$, such studies require detailed thermodynamic states to be known at every process paths of the cycle or plant, making their analyses difficult for both designers and operators of desalination plants. Hence, there is an urgency to develop a simple, practical and yet accurate thermodynamic framework (no exergy destruction calculations of individual process) that avoids any misunderstandings regarding the status of energy derived from different sources. An accurate evaluation methodology will facilitate the rapid development and better implementation of desalination options, thereby facilitating the water industry's aim of attaining the goal of sustainable seawater desalination.

${ }^{1}$ Water Desalination and Reuse Centre, King Abdullah University of Science \& Technology, Thuwal, Kingdom of Saudi Arabia. ${ }^{2}$ Department of Mechanical and Construction Engineering, Northumbria University, Newcastle Upon Tyne, UK. ${ }^{凶}$ email: muhammad.w.shahzad@northumbria.ac.uk 
(at $\mathrm{T}=$ adiabatic)

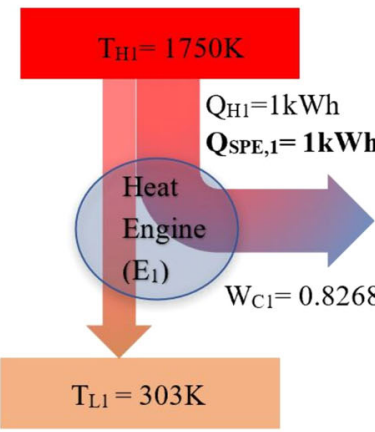

(a) (at $\mathrm{T}<$ adiabatic)

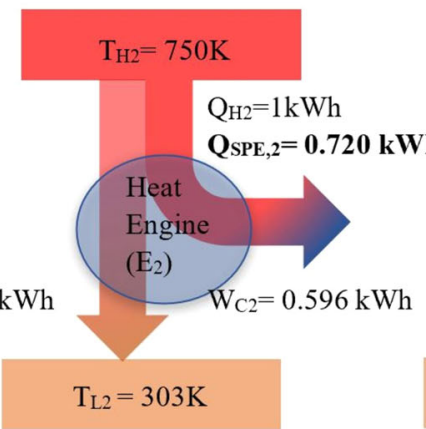

(b) (at $\mathrm{T}<$ adiabatic)

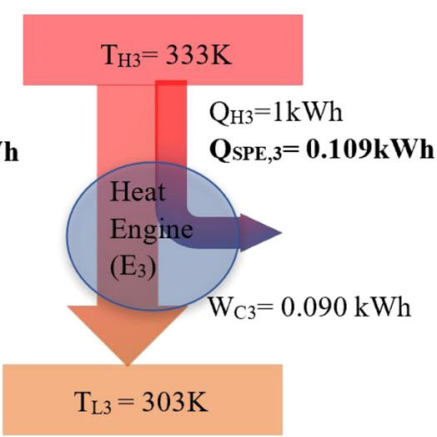

(c)

Fig. 1 Maximum work potential of simple thermodynamic cycles. a High- and low-temperature reservoirs of engine $E_{1}$ are set at the same common temperature platform, $T_{\text {adia }}$ and $T_{\mathrm{o}}$. As such, the standard primary energy, $Q_{\mathrm{SPE}}$ is demonstrated to equal to $Q_{\mathrm{H} 1}$. b, c Reservoirs temperature are set at their designed conditions and hence $Q_{S P E}$ is not equal to $Q_{H}$.

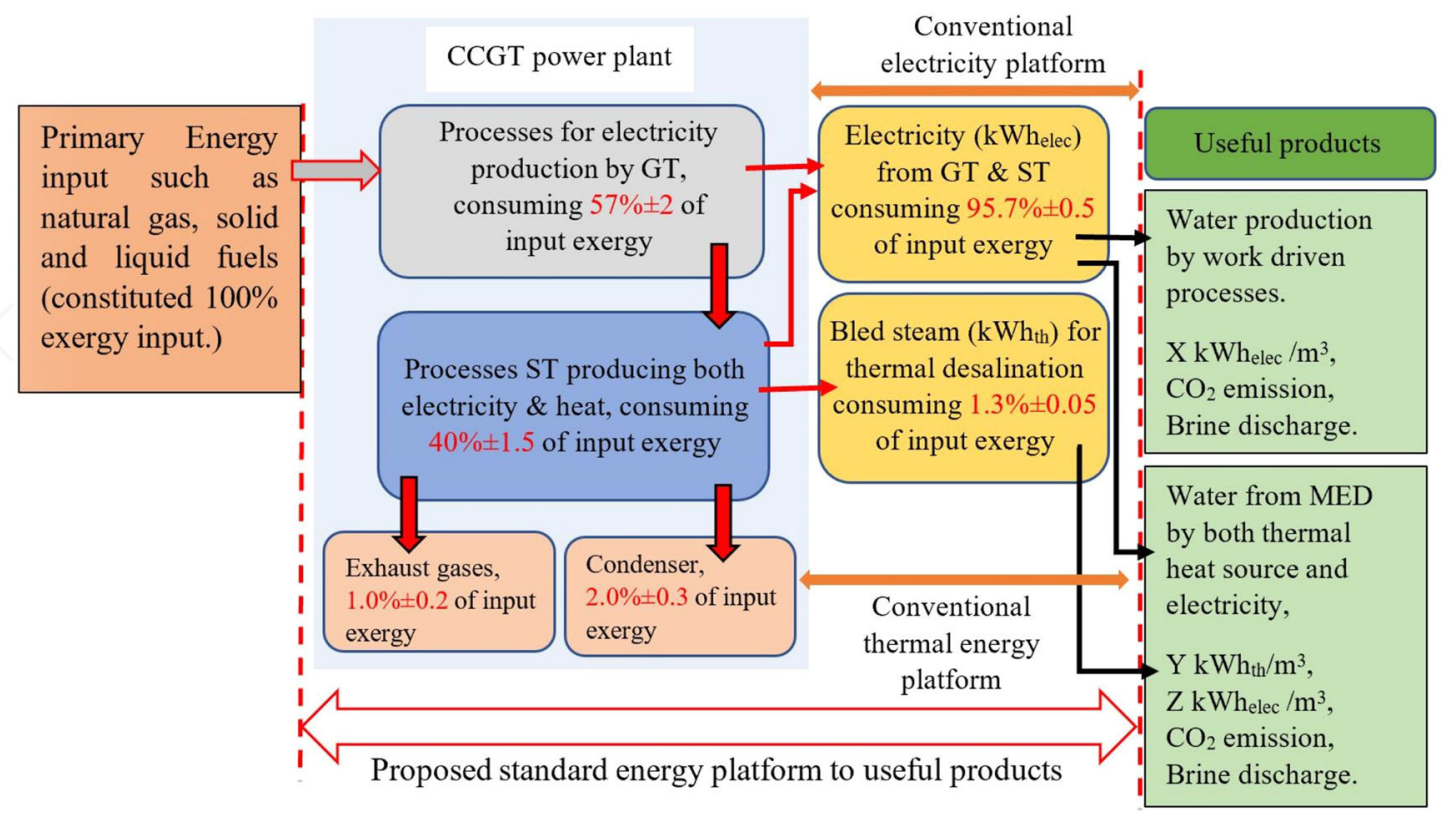

Fig. 2 Primary energy distribution in combined power and water plant. Primary energy distribution in combined power and water plant.

In this paper, two challenges are addressed. Firstly, the importance of having a common energy platform to compare the diverse range of desalination processes is underscored. The term standard primary energy $\left(Q_{\mathrm{SPE}}\right)$ has been introduced as that quantity that would be required for a process with a source at the adiabatic flame temperature of the fuel and a sink at ambient temperature. The relative fractions of $Q_{S P E}$ consumption in a combined cycle gas turbine (CCGT) plant can replicate meaningfully the conversion efficiency of every type of derived energy produced. Secondly, for the convenience of professionals working in the desalination industry, suitable conversion factors (CFs) are developed using the common temperature platform. Specifically this is made for the ratios of (i) $Q_{S P E}$ to electricity-based work output ( $W_{\text {elec }}$ ) and (ii) $Q_{S P E}$ to $Q_{a}$ for a thermally driven desalination plant. With a causal calibration of best available conversion plants, any reported performance data of similar desalination plants available in the literature, expressed in $\mathrm{kWh}$ elec $/ \mathrm{m}^{3}$ or $\mathrm{kWh} \mathrm{ht}_{\mathrm{th}} / \mathrm{m}^{3}$, can be accurately transformed to the common energy platform of $\mathrm{kWh}_{\mathrm{SPE}} / \mathrm{m}^{3}$ by these factors.

Further to recent report on improvement to potable water flux in membrane seawater desalination processes ${ }^{25}$, major improvements in future seawater desalination processes are likely due to innovative methods and processes being developed. Such improvements in desalination processes can be achieved either (i) by overcoming material challenges through improved membranebased systems with novel nano-structures materials, better fouling control $^{26-31}$, and appropriate use of associated models ${ }^{32,33}$ and / or (ii) via a better thermodynamic synergy from temperaturecascaded efficient concentrated solar power (CSP) integrated hybrid processes for green electricity generation and heat-driven regenerative multi-effect seawater desalination processes ${ }^{34-38}$.

The best available co-generation system for the production of electricity and desalinated water is the combined cycle gas turbines (CCGT) plant, having a global average energetic conversion efficiency of $55 \pm 3 \%$ as shown in Fig. $2^{39}$. Natural gas has been the optimal choice for CCGTs due to the single carbon atom structure of fuel, which results in less $\mathrm{CO}_{2}$ per unit of energy and is thus relatively environmentally favorable. In our earlier work ${ }^{40}$, a thorough exergy destruction analysis of a typical CCGT, where their dissipation proportions were expressed as fractions of total exergy input, were conducted. These fractions were apportioned correspondingly to the consumption of the 


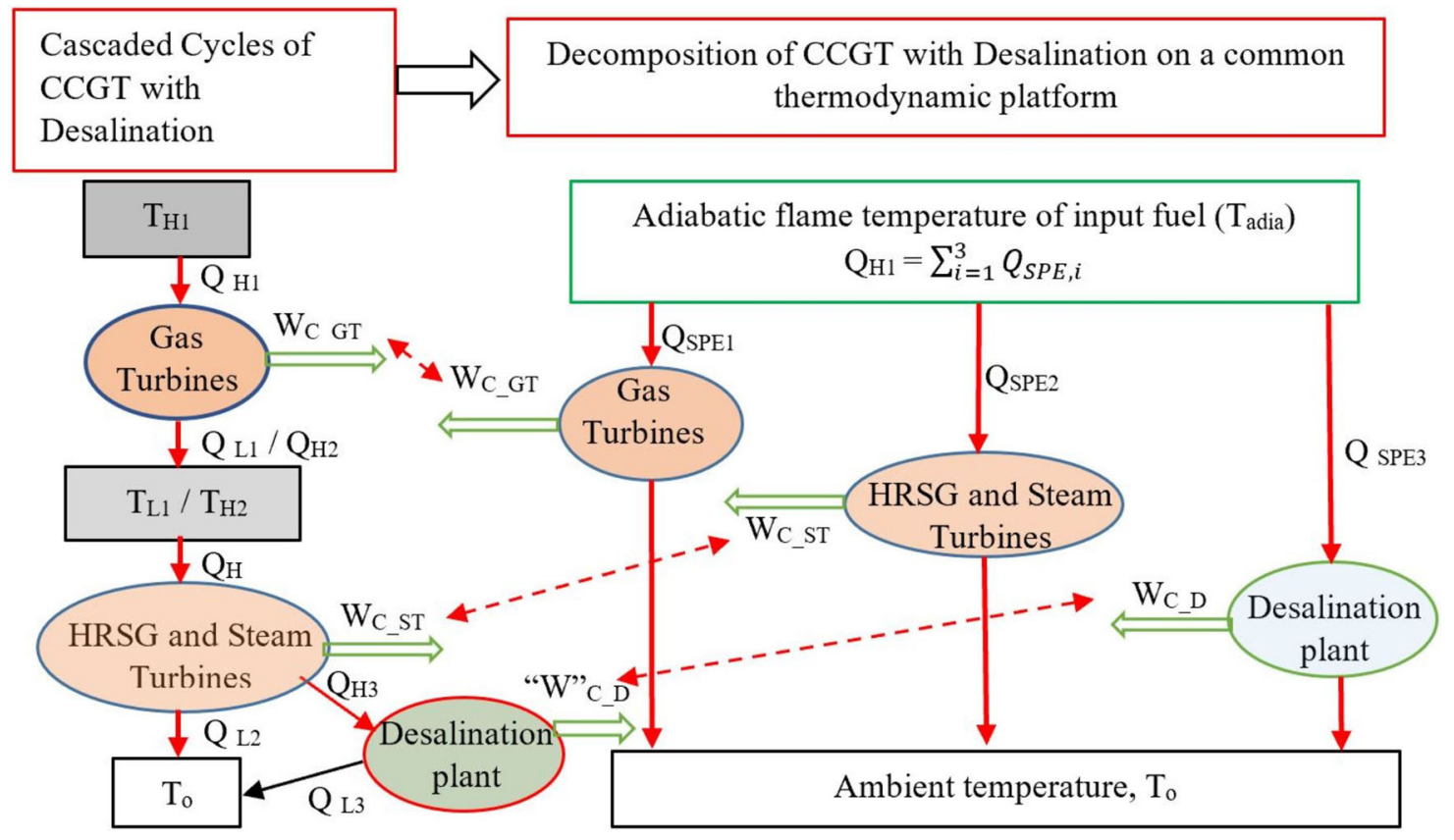

Fig. 3 A decomposition of temperature-cascaded heat engines. A decomposition of temperature-cascaded heat engines.

primary energy input, embedding both the quantity and quality of all derived energy generated by the CCGT plant. Although the exergy concept is thermodynamically rigorous, it needs detailed thermodynamic states of processes of all cascaded cycles, which were scarcely reported in many reports of large plants. Furthermore, the scope of computations for each and every cycle, stretching from power plants to hybrid separation processes, have been perceived as difficult to follow by many utility planners, engineers and operators.

\section{RESULTS AND DISCUSSION}

To illustrate the use of our thermodynamics framework, a typical commercial scale combined cycle gas turbines plant with a nominal primary energy input of $2000 \mathrm{MW}$ is examined. We assumed the average efficiencies of the processes involved in the components of CCGT, i.e., the turbines and heat exchange processes. The co-generation scheme is illustrated in Fig. 3 where electricity is generated by both gas and steam turbines cycles and potable water by seawater desalination processes. The latter comprises proven commercial scale plants such as the Multi-Effect Desalination-Thermal Vapor Compressor (MED-TVC) methods that utilized the low-grade steam that were bled from the steam turbines. Using only the measured information for a combination of CCGT with desalination, the corresponding heat input and Carnot work for each cascaded cycle can be evaluated readily. As outlined in Supplementary Table 1, the main inputs are the process-average temperatures and the transfer of heat experienced by key components of CCGT. Table 1 summarizes the key parameters that were needed, the computation of Carnot work, the standard primary energy $\left(Q_{\mathrm{SPE}}\right)$, as well as the conversion factors (CF) when the derived energy (electricity and thermal heat input) were known at their design or operating temperature levels. Based on a nominal fuel input of $2000 \mathrm{MW}$, the Supplementary Table 2 material gives the detailed calculations for determining the conversion factors of electricity and thermal energy consumptions.

The distributions of $Q_{\text {SPEE}}, W_{\mathrm{a}}, W_{\text {Carnot }}$, second law efficiency, and the conversion factors can be evaluated at temperatures corresponding to the respective processes or cycles. The details of these computations for the major components are tabulated in Supplementary Table 2. A graphical chart, summarizing the consumption of standard primary energy and the derived energy are shown in Fig. 4, while the corresponding conversion factors, namely $\mathrm{CF}_{\text {elec }}$ and $\mathrm{CF}_{\text {th }}$ are also tabulated in Table 2.

\section{Conversion factors}

Table 2 depicts how the conversion factors can be used to transform the conventional specific energy consumption from a work- and heat-driven desalination plants into the respective standard primary energy $\left(Q_{\mathrm{SPE}}\right)$. For example, the average specific energy efficiency of Seawater Reverse Osmosis (SWRO) plants, say $4.5 \mathrm{kWh}$ elec $/ \mathrm{m}^{3}$, would require the specific standard primary energy of $Q_{\mathrm{SPE}}=7.80 \mathrm{kWh} \mathrm{SPE}_{\mathrm{SE}} / \mathrm{m}^{3}$, where the $\mathrm{CF}_{\text {elec }}=1.733$ is the weighted value for the electricity generation from both turbines. Similarly, the average consumption of low-grade heat by the thermally driven MED plants, say $60.0 \mathrm{kWh}$ th $/ \mathrm{m}^{3}$ and $1.0 \mathrm{kWh}$ eled $\mathrm{m}^{3}$ can be normalized to the standard primary energy consumption, i.e., total $Q_{\mathrm{SPE}}$ of MED processes $=9.23 \mathrm{kWh} \mathrm{hPE}_{\mathrm{SP}} / \mathrm{m}^{3}$, where the conversion factors for electricity and thermal sources are $\mathrm{CF}_{\text {elec }}=$ 1.733 and $\mathrm{CF}_{\mathrm{th}}=0.125$, respectively, and the latter is normalized the low-grade heat consumption of MED plants. As for the MEDTVC and MSF plants, the thermal conversion factors are found to be 0.299 and 0.252 , respectively due to higher steam inlet temperatures. The key point to note is that $Q_{S P E}$ is the common energy platform for all methods. The amount of dissipative losses incurred by all practical desalination methods can be compared directly with respect to the thermodynamic limit. It can be concluded that electricity is a high-grade derived energy whilst the bled steam at low-pressure and temperature is a low-grade derived energy. Thus, the general assumption of equal parity for all types of derived energy is obviously invalid.

\section{Thermodynamic limits}

In the literature, two ideal limits to express the least work of seawater desalination have been reported where the Gibbs equation is used to predict these limits by considering the salinity and temperature of seawater. Firstly, the universal thermodynamic limit where both the external and internal processes of a desalination plant are deemed reversible and hence, it is system independent as there is zero recovery. For a normal seawater at $3.5 \%$ solute by weight and $25^{\circ} \mathrm{C}$, the universal TL is $0.78 \mathrm{kWh} / \mathrm{m}^{3}$ 
Table 1. The key parameters, $W_{\mathrm{C}}, Q_{\mathrm{SPE}}$, and CF of CCGT plant.

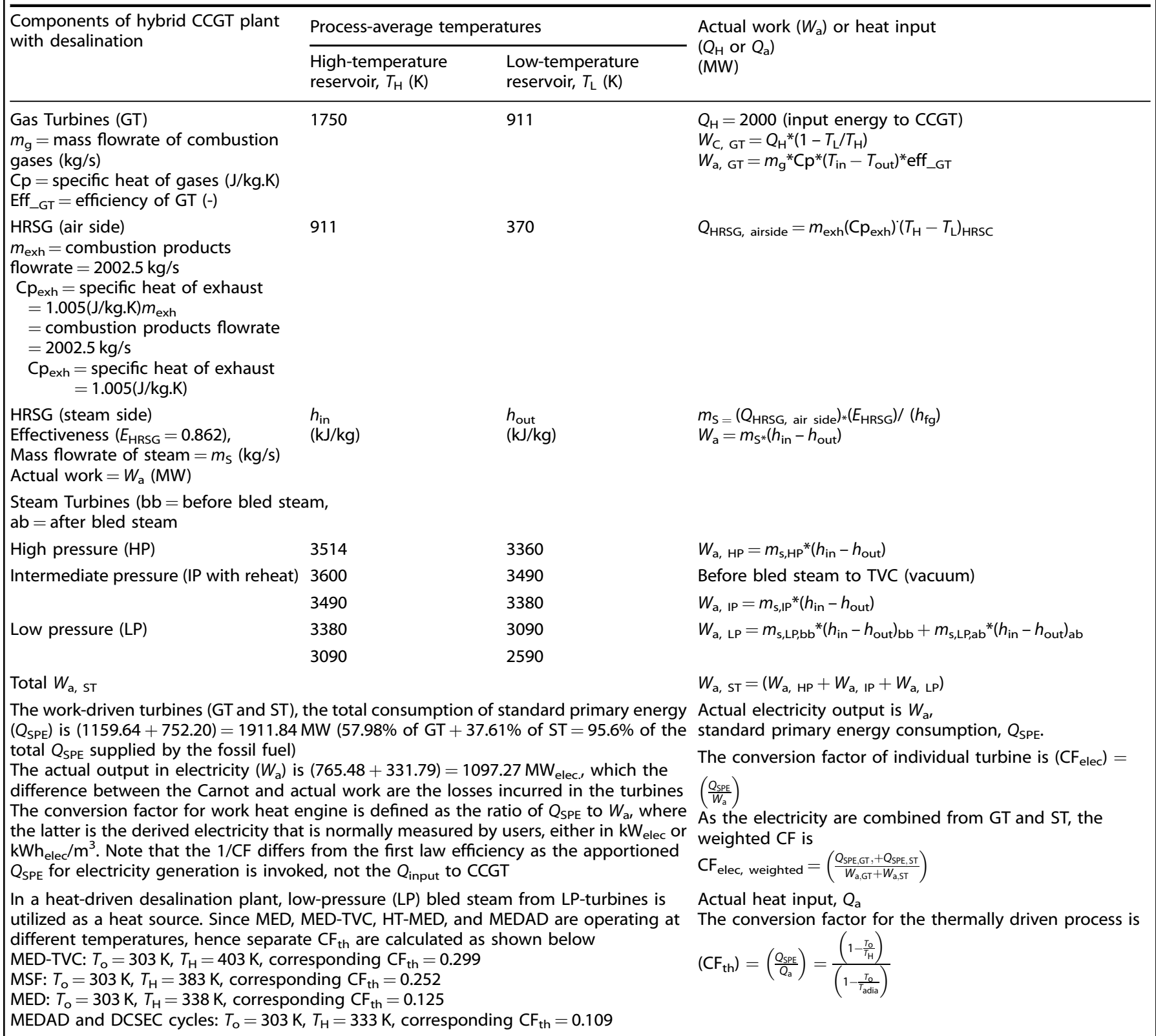

or $2.8 \mathrm{~kJ} / \mathrm{kg}$. In additional to the salinity of seawater and temperature constraints of an open system, a second ideal limit has been reported with an open system concept except that it has a finite rate water recovery. This approach corresponds to the endoreversible thermodynamics literature ${ }^{41-44}$, and the second type of ideal limit for practical desalination plants is classified here as the "endoreversible thermodynamic limit", other might label this simply as the theoretical minimum at finite recovery. Figure 5 present universal and endoreversible thermodynamic limits schematics. It has inherently incurred exergy losses, caused by a finite rate of water recovery imposed onto it. The difference between these ideal limits can be attributed to the combined salinity constraints and the inherent irreversibility from finite recovery, as shown in Table 3. In general, either of the abovementioned ideal limits can be used as a benchmark for comparison purposes, depending on the needs of application or analysis. An universal TL benchmark that is essentially system independent has been adopted as most of the reported literature provide the energy performances in $\mathrm{kWh}_{\text {elec }}$ or $\mathrm{kWh}_{\text {th }}$ per $\mathrm{m}^{3}$ without supplying the recovery ratio of desalination plants.

\section{Processes comparison at common platform}

The data available for 60 seawater desalination plants based on assorted processes, stretching from 1983 to the present day, were revisited ${ }^{45-56}$. Using such a common primary energy platform, their specific energy efficiency, expressed in $\mathrm{m}^{3} / \mathrm{kWh}_{\mathrm{SPE}}$, were retrospectively standardized by the relevant conversion factors. The revised and equitable energy efficiency comparison is shown in Fig. 6. Based on the universal thermodynamic limit (TL) of seawater desalination, the corresponding maximum potable water could be desalinated is $1 / 0.9437=1.059 \mathrm{~m}^{3} / \mathrm{kWh}_{\mathrm{SPE}}$. By comparing the water production rates per unit $Q_{\text {SPE }}$ of practical methods from 1983 till now, all existing desalination processes are operating their energy 


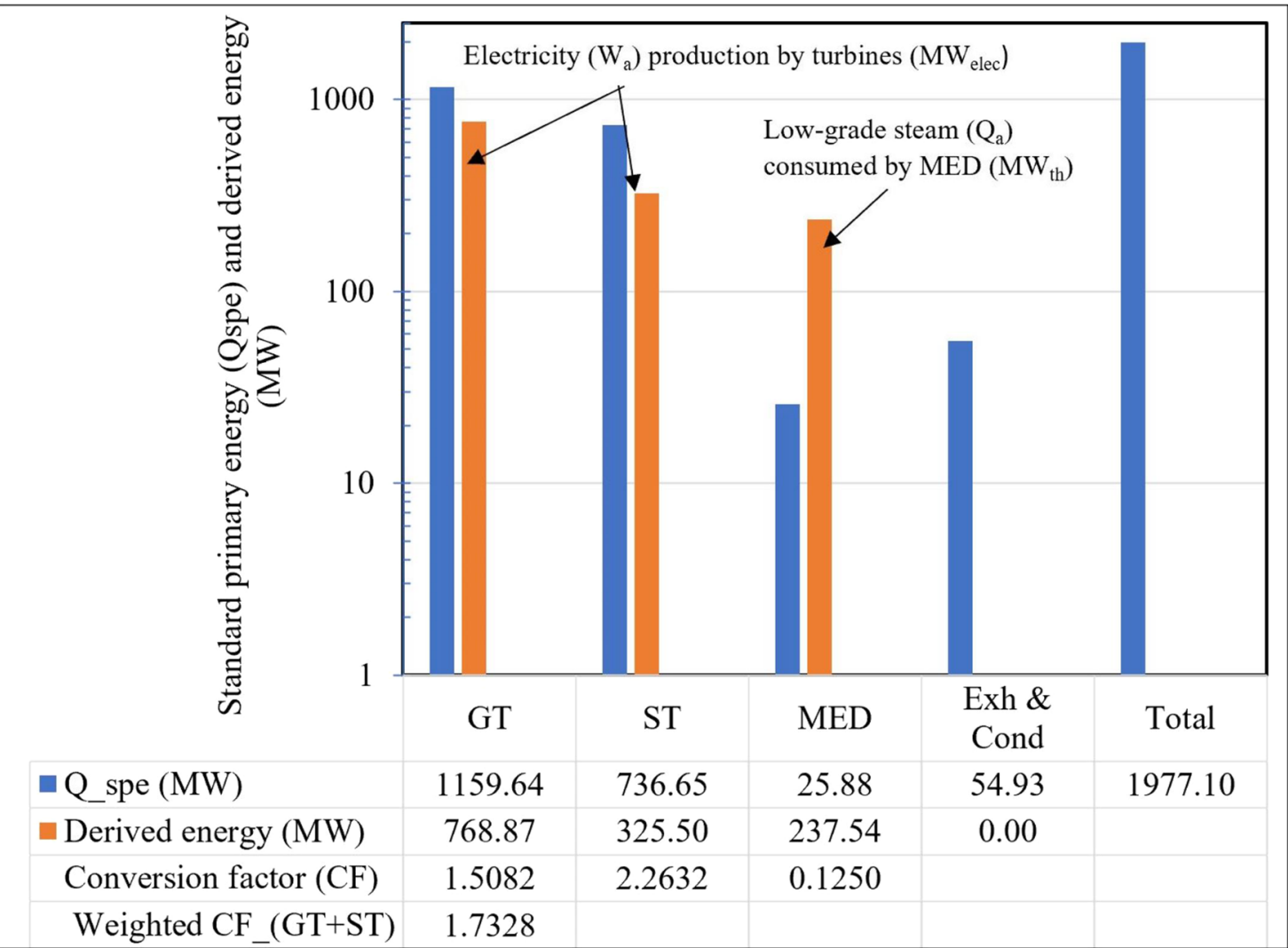

Fig. 4 The consumption of standard primary energy by different processes. The consumption of standard primary energy by different processes.

Table 2. The conversion from $W_{\mathrm{a}}$ or $Q_{\mathrm{a}}$ to a common platform of $Q_{\mathrm{SPE}}$.

\begin{tabular}{|c|c|c|c|c|}
\hline $\begin{array}{l}\text { CCGT power plant } \\
\text { with MED for } \\
\text { desalination }\end{array}$ & $\begin{array}{l}\text { Actual work or } \\
\text { heat } \\
\text { input (MW) }\end{array}$ & $\begin{array}{l}\text { Standard primary energy at } \\
\text { common energy } \\
\text { platform (MW) }\end{array}$ & $\begin{array}{l}\text { Specific energy } \\
\text { consumption as reported } \\
\text { in literature }\end{array}$ & $\begin{array}{c}\text { Specific standard primary consumption at the } \\
\text { common energy platform, computed with an average } \\
\text { value. }\left(Q_{\mathrm{SPE}} / \mathrm{m}^{3}\right)\end{array}$ \\
\hline \multirow{2}{*}{$\begin{array}{l}\text { Gas and steam } \\
\text { turbines } \\
\text { (electricity, MW) }\end{array}$} & $\begin{array}{c}W_{\mathrm{a}}=1094.37 \\
\text { (electricity) }\end{array}$ & $Q_{\mathrm{SPE}}=1896.30$ & $\begin{array}{c}\text { SWRO } \\
3.5 \text { to } 5.5 \mathrm{kWh} \text { elec } / \mathrm{m}^{3}\end{array}$ & $\begin{array}{c}Q_{\mathrm{SPE}}=4.5(1.733) \\
=7.80 \mathrm{kWh} \\
\mathrm{SPE}\end{array}$ \\
\hline & $\mathrm{CF}_{\text {elec }}$ & $\begin{aligned} c= & 1896.30 / 1094.37 \\
= & 1.733\end{aligned}$ & & \\
\hline MED & & 0.125 & $\begin{array}{c}\text { MED } \\
40 \text { to } 80 \mathrm{kWh}_{\mathrm{th}} / \mathrm{m}^{3} \\
\text { and } \\
0.8 \text { to } 1.2 \mathrm{kWh} \text { elec } / \mathrm{m}^{3}\end{array}$ & $\begin{aligned} Q_{\mathrm{SPE}} & =60(0.125)+1.0(1.733) \\
& =9.23 \mathrm{kWh} \mathrm{h}_{\mathrm{SPE}} / \mathrm{m}^{3}\end{aligned}$ \\
\hline
\end{tabular}

Table 3. The comparison between the universal and endoreversible thermodynamic limits.

Salinity of normal seawater at $3.5 \%$ by weight and Universal Thermodynamics limit (TL) Endoreversible Thermodynamic limit ${ }^{41-43,54}$ $25^{\circ} \mathrm{C}^{12,13}$

\begin{tabular}{|c|c|c|}
\hline Least work & $0.78 \mathrm{kWh} / \mathrm{m}^{3}$ or $2.8 \mathrm{~kJ} / \mathrm{kg}^{12,13}$ & $\begin{array}{l}1.06 \mathrm{kWh} / \mathrm{m}^{3} \text { at } r=0.5 \text { or } 3.8 \mathrm{~kJ} / \mathrm{kg} \\
\text { For example, the endoreversible TL at } 50 \% \text { recovery ratio is } \\
\text { extracted from }\end{array}$ \\
\hline$Q_{S P E}$ & $\begin{array}{l}=W_{\mathrm{TL} \text { _universal }} /\left(1-T_{\mathrm{O}} / T_{\text {adia }}\right) \\
=0.9437 \mathrm{kWh} \\
\mathrm{SPE} / \mathrm{m}^{3}\end{array}$ & $\begin{array}{l}=W_{\mathrm{TL} \_ \text {endoreversible }} /\left(1-T_{\mathrm{o}} / T_{\mathrm{adia}}\right) \\
=1.282 \mathrm{kWh} \mathrm{SPE} / \mathrm{m}^{3}\end{array}$ \\
\hline $\begin{array}{l}\text { Actual } Q_{\mathrm{SPE}} \text { to } Q_{\mathrm{TL}} \\
\text { e.g., the average energy consumption }\left(W_{\mathrm{a}}\right) \text { of } \\
\mathrm{SWRO}=3.5 \mathrm{kWh} \text { elec } / \mathrm{m}^{3}\end{array}$ & $\begin{array}{l}=Q_{\mathrm{SPE}, \mathrm{a}} / Q_{\mathrm{SPE}, \mathrm{TL} \text {-universal }} \\
=\left(3.5^{*} \mathrm{CF}_{\mathrm{Peec}}\right) /(0.9437)=6.59 \\
\text { or } 15.1 \% \text { of universal } \mathrm{TL}\end{array}$ & $\begin{array}{l}=Q_{\mathrm{SPE}, \mathrm{a}} / Q_{\mathrm{SPE}, \mathrm{TL}} \text { endoreversible } \\
=\left(3.5^{*} \mathrm{CF} \mathrm{F}_{\mathrm{elec}}\right) /(1.282)=4.85 \text { or } 20.6 \% \text { of endoreversible } \mathrm{TL}\end{array}$ \\
\hline
\end{tabular}


(a)

Moles of solution, $\left(\boldsymbol{N}_{\boldsymbol{F}}\right)$, in closed

volume is at $3.5 \%$ by weight and $25^{\circ} \mathrm{C}$

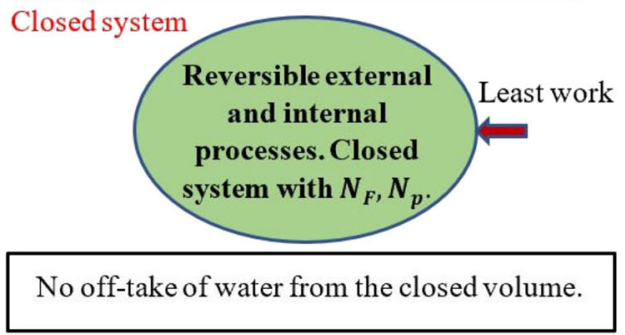

(b)

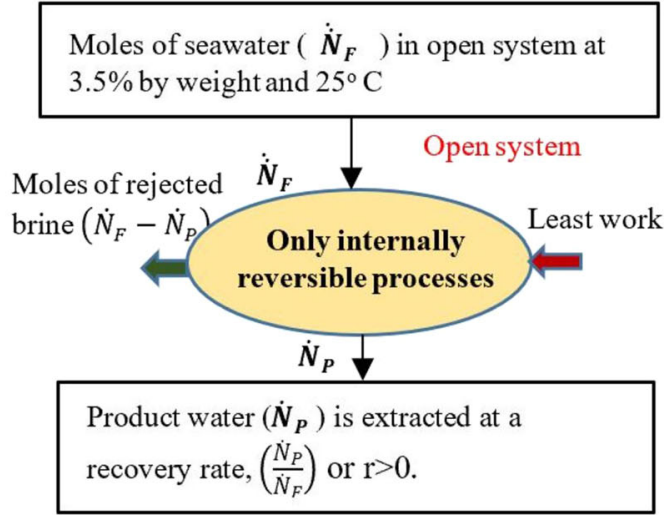

Fig. 5 Thermodynamic limits. a Universal, b Endoreversible.

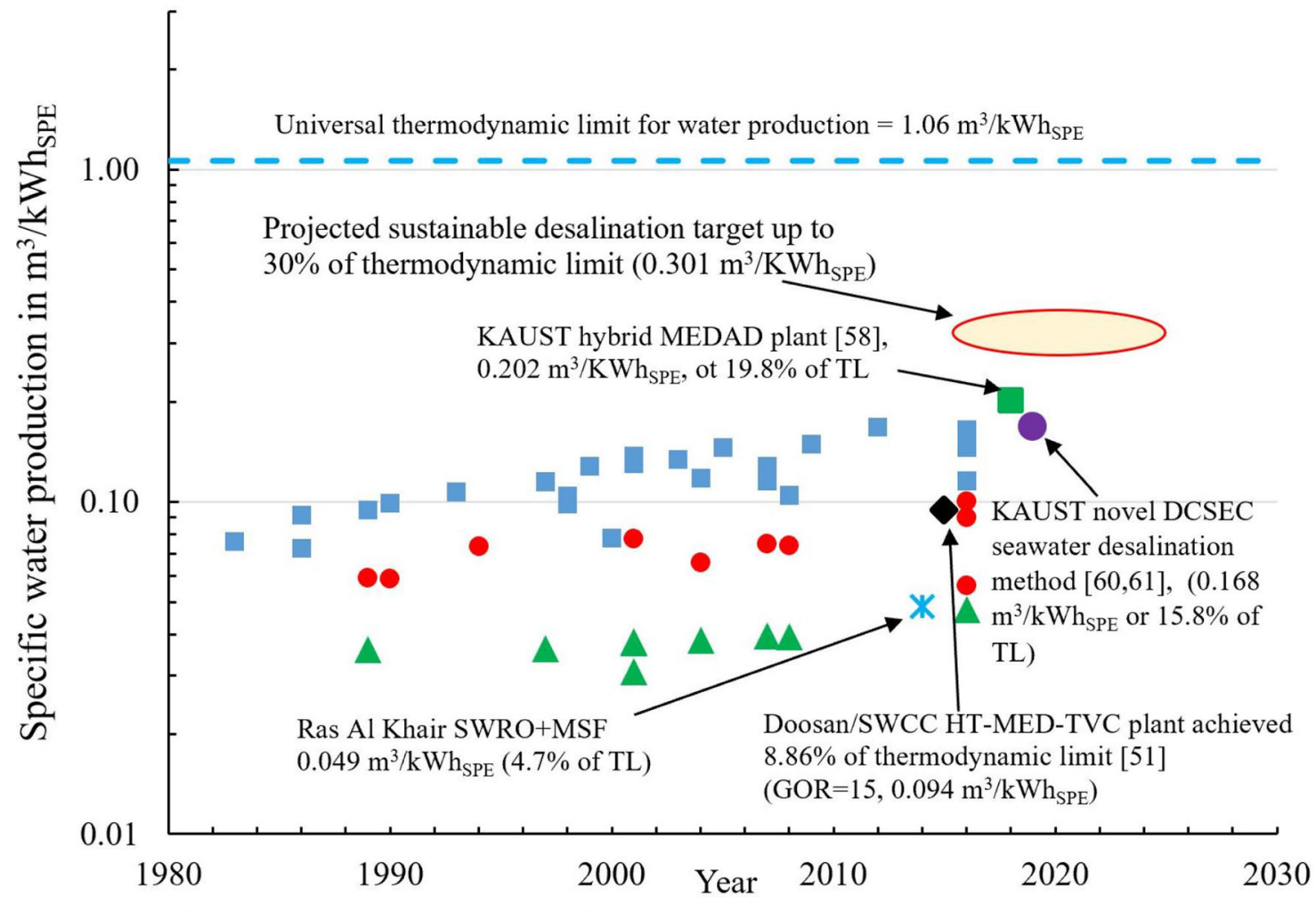

- SWRO $\bullet$ MED $\triangle$ MSF $\bullet$ Doosan_HT_MED $\square$ KAUST_MEDAD $\bullet$ KAUST_DCSEC $\propto$ Ras Al Khair_MSF+RO

Fig. 6 Energy efficiency comparison of seawater desalination processes. Energy efficiency comparison of seawater desalination processes.

efficiency at $<16 \%$ of the TL. For example, the SWRO had its efficacy trend improved from $7-15.7 \%$ and the MED-TVC from 5 to $10 \%$. This method is observed to have higher energy efficiency due primarily that the membranes are handling liquid separation across the osmotic pressures. Conventional thermally driven methods, such as the Multi-Stage Flashing (MSF) and MED recorded a lower efficacy. In 2015, Doosan corporation (South Korea) tested an industrial pilot of nominal water production of $400 \mathrm{~m}^{3} /$ day, a high-temperature MED integrated with the thermal vapor compressor (TVC), at Yanbu (Saudi Arabia) and achieved $8.86 \%$ of $\mathrm{TL}\left(\mathrm{GOR}=15,0.094 \mathrm{~m}^{3} / \mathrm{kWh}_{\mathrm{SPE}}\right)^{57}$. However, with hybridization of two or more processes, the hybrid SWRO and MSF plant at Ras Al Khair recorded a slight improvement as compared to conventional systems, from $0.04 \mathrm{~m}^{3} / \mathrm{kWh}_{\mathrm{SPE}}$ to $0.05 \mathrm{~m}^{3} / \mathrm{kWh}_{\text {SPE }}$.

\section{Processes for future sustainability}

At KAUST, the authors have conducted hybrid experiments on Multi-Effect Desalination and Adsorption Desalination (MEDAD) pilot $^{58-64}$ operated at $333 \mathrm{~K}$. The thermodynamic synergy effect of $A D$ lowers the bottom-brine temperatures to $7^{\circ} \mathrm{C}$, permitting higher water fluxes in MED stages caused by higher temperature difference between feed and equilibrium stage vapor. Also, liquid flashing phenomena have been observed in MED stages where 


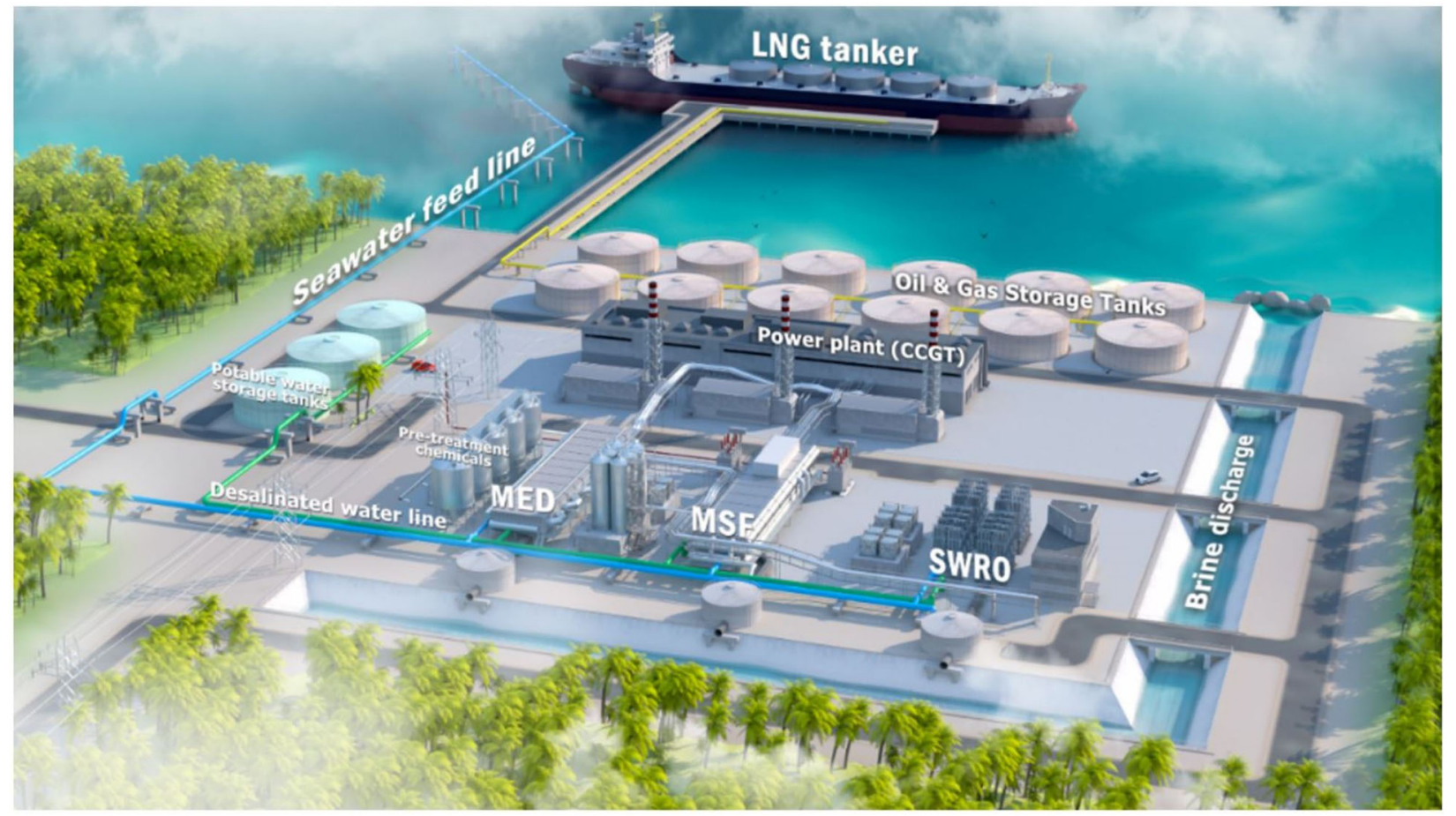

Fig. 7 A pictorial representation of combined cycle gas turbines (CCGT) plant. A pictorial representation of combined cycle gas turbines (CCGT) plant.

excess enthalpy was derived as the equilibrium vapor state dropped below incoming feed temperature.

Also recent published work on solar-powered, multi-stage direct contact spray evaporation and condensation (DCSEC) with microbubble enhancement for seawater desalination yielded a specific energy efficiency of $0.168 \mathrm{~m}^{3} / \mathrm{kWh}_{\mathrm{SPE}}$ or about $15.8 \%$ of the $\mathrm{TL}^{65,66}$. The stark improvement in the energy efficiency of DCSEC method is attributed to the combination of the simplicity of spray evaporation, injection of micro-bubbles for surface area enhancement and the heat recovery from the condensate in the multistage design. Based on these trends in energy efficiency improvement of thermally driven seawater desalination processes, the target for sustainable seawater desalination at $30 \%$ of the TL is projected for the next decade; a similar 2nd Law efficiency up to $80 \%$ has been demonstrated in the allied area of heat engines, namely by CCGT plants.

Some may pose a scenario where the fuel energy is burned directly in boilers to generate solely the low-grade steam for powering the thermally driven processes, and ignore potential for integrating the more efficient CCGT. In general and certainly at the large-scale, all designers should be incorporating more innovative processes to maximize the exergy of primary energy. The Laws of Thermodynamics dictate only the permissible boundaries or limits predicated by innovative solutions. Hence, the thermodynamicbased conversion factors (CFs) have to be established based upon the best available power plants, i.e., the CCGT. Should there be significant improvement made in future power plants, the conversion factors can be updated accordingly, for example, the advent of green electricity from renewable sources such as solar, wind and hydro, and from "Blue Energy". Processes in the latter category envisage the production of energy from the controlled mixing of seawater and fresh water and this would have the advantage that it can be operated continuously unlike processes based on solar and wind energy ${ }^{67}$. The main process in this area and the process that motivated this work is Pressure-Retarded Osmosis (PRO). However, analyses that include the supply of green electricity and low-grade heat sources to the CFs will be a topic for future studies.

\section{METHODS}

In contrast to exergy analysis approach, a simpler and yet accurate approach of equivalent heat engines is proposed where only minimal input information of key processes or cycles of conversion plant are needed, namely the work $\left(W_{\mathrm{a}}\right)$ or heat input $\left(Q_{\mathrm{H}}\right)$, the process average of high $\left(T_{H}\right)$, and low $\left(T_{L}\right)$ temperatures of heat reservoirs. Presenting the example of a CCGT with a nominal fuel energy input of $2000 \mathrm{MW}$, the respective ideal or Carnot work of temperature-cascaded heat or reverse engines of CCGT are readily computed, for example, the work engines of gas and steam turbines, as well as the bled steam-powered desalination plants (zero physical work output) as shown in Fig. 3.

With this approach, the Carnot work of respective heat engines of CCGT can be "decomposed" individually with respect to the maximum temperature difference between two physical limits predicated by the input fuel and the ambient states. Emulating the same Carnot work as per design of actual cycle, it is then normalized to the respective standard primary energy $\left(Q_{\mathrm{SPE}}\right)$ at the common temperature platform. The thermodynamic consistency of the framework could be confirmed by summing all $Q_{S P E}$ of cascaded cycles to yield the primary fuel energy at input. It is envisaged that one of the most plausible and optimal co-generation designs of a hybrid power plant with proven seawater desalination processes is illustrated pictorially in Fig. 7. Here, both electricity and low-grade heat sources are produced in-situ, providing the optimal grid power and capacity of potable water. Such an integrated power and water system is designed with maximum temperature cascade (hence minimum dissipative losses) for power generation and low-grade heat utilization.

To recap, the decoupling framework requires two requisites. Firstly, the matching of Carnot work of each cascaded engine of CCGT, as per designed temperatures, to the ideal engines at the common temperature platform for the computation of standard primary energy $\left(Q_{S P E}\right)$, as shown in Fig. 3. Secondly, by summing all the standard primary energy ( $\left.Q_{S P E}\right)$ available from the decomposed engines, one obtains the equivalent calorific value of fuel supplied to the CCGT.

Owing to the common temperature platform of decomposed engines, the ratio of Carnot work $\left(W_{\mathrm{c}}\right)$ to the standard primary energy $\left(Q_{\mathrm{SPE}}\right)$ is equally applicable to either a single individual engine or all decomposed 
engines of the CCGT plant, i.e.,

$\frac{\sum_{i=1}^{n}\left(W_{\mathrm{C}, i}\right)}{\sum_{i=1}^{n}\left(Q_{\mathrm{SPE}, i}\right)}=\frac{\left(T_{\text {adia }}-T_{\mathrm{o}}\right)}{T_{\text {adia }}}=\left(\frac{W_{\mathrm{c}}}{Q_{\mathrm{SPE}}}\right)_{i}$

where " $i$ " refers to a specific engines and " $n$ " denotes the total number of engines. The temperatures, $T_{\text {adia }}$ and $T_{0}$, are process-average adiabatic flame and ambient temperatures, respectively. As the first and third terms of Eq. 1 are equivalent to the common temperature ratio, i.e., $\frac{\left(T_{\text {dadia }}-T_{0}\right)}{T_{\text {adid }}}$, the terms can be equated to each other and re-arranged to give the fractional form of process heat or work to their respective total, i.e.,

$\frac{Q_{\mathrm{H}, i}}{\sum_{i=1}^{n}\left(Q_{\mathrm{H}, i}\right)}=\frac{W_{\mathrm{c}, i}}{\sum_{i=1}^{n}\left(W_{\mathrm{C}, i}\right)}$

Before moving to illustrative examples, it is noted that those seeking thermodynamic details should consult Supplementary Table 1 supplied in the article where it will be seen that the framework adheres to the Second Law.

\section{Electricity-driven desalination processes}

As electricity is one of the convenient forms of derived energy, it is used to power work-driven membrane-based reverse osmosis (RO) desalination processes. By defining the 2nd Law Efficiency as $\eta^{\prime \prime}=\frac{W_{a}}{W_{c}}$ for an engine, where the actual work input is normally known via electricity consumption of processes. From the decomposed gas and steam turbines that produced electricity of a CCGT plant, a conversion factor (CF) can now be defined, based on the consumption of the standard primary energy of these engines to the actual electricity output, i.e.,

$\mathrm{CF}_{\text {elec }}=\frac{\sum_{i=1}^{n=2} Q_{\mathrm{SPE}, i}}{\sum_{i=1}^{n=2} W_{a, i}}$

where the subscripts $\left(i_{i=1}\right)$ and $(i=2)$ refer to the contributions from gas and steam turbines of CCGT, respectively. Note that the denominator term is the actual work, $W_{\mathrm{a}}$. The latter can be related to the Carnot work $\left(W_{C}\right)$ via the empirical 2nd Law Efficiency $\left(\eta^{\prime \prime}\right)$ of the respective work producing cycle. Equation 3 can be further expressed as a function based on the common temperature platform ratio and the sum of work-weighted second law efficiency of the processes, i.e., $\sum_{i=1}^{n=2}\left(\frac{W_{c, i}}{W_{c, T}} \eta_{i}^{\prime \prime}\right)$.

$\mathrm{CF}_{\text {elec }}=\frac{\sum_{i=1}^{n=2} Q_{\mathrm{SPE}, i}}{\sum_{i=1}^{n=2} W_{a, i}}=\left(\frac{\sum_{i=1}^{n=2}\left(\frac{W_{\mathrm{C}, i}}{1-\frac{I_{o}}{T_{\text {ddia }}}}\right)}{\sum_{i=1}^{n=2}\left(W_{\mathrm{C}, i} \eta_{i}^{\prime \prime}\right)}\right)=\frac{1}{\left(1-\frac{T_{o}}{T_{\text {adia }}}\right) \sum_{i=1}^{n=2}\left(\frac{W_{\mathrm{C}, i}}{W_{\mathrm{C}, \mathrm{T}}} \eta_{i}^{\prime \prime}\right)}$,

Note that the subscripts " $\mathrm{c}$ " and "a" refer to the Carnot and actual work, respectively. $W_{C, T}$ refers to the total Carnot work of heat engines. The temperatures $T_{\text {adia }}$ and $T_{0}$ are the process-average adiabatic flame temperature (with due allowance for the excess-air combustion) and ambient temperature, respectively.

Although Eq. 4 has generated an expression for the desired figure of merit, $\frac{\sum_{i=1}^{2} Q_{S P E, i}}{\sum_{i=1}^{2} W_{\mathrm{a}, i}}$ this function is a combination of the common temperature ratio platform and the work-weighted second law efficiency, i.e., $\bar{\eta}^{\prime \prime}=\sum_{i=1}^{n=2}\left(\frac{W_{\mathrm{C}, i}}{W_{\mathrm{C}, \mathrm{T}}} \eta_{i}^{\prime \prime}\right)$.

Superficially, the inverse of $\mathrm{CF}_{\text {elec }}$ may appear similar to the conventional energy efficiency of a power plant. However, a closer examination of its derivation reveals a fundamental difference where it employs the standardized $Q_{S P E}$, and not $Q_{H}$. The latter term expresses only the quantitative aspect and makes no allowance for the quality of energy consumed.

\section{Thermally driven desalination processes}

For a thermally driven multi-effect desalination system (MED), the lowgrade heat supplied yielded zero physical work output as of heat engines. Instead, it produces a finite rate of potable water via evaporation and condensation processes. The Carnot work potential of the low-grade steam entering the MED is computed and it is then decomposed to the equivalent standard primary energy $\left(Q_{\mathrm{SPE}}\right)$ at the common energy platform. Hence, the conversion factor $\left(\mathrm{CF}_{\mathrm{th}}\right)$ of MED desalination is defined as the ratio of standard primary energy consumption to the actual heat supply, $Q_{a}$, i.e.,

$$
\left(\mathrm{CF}_{\mathrm{th}}\right)=\left\{\frac{\left(Q_{\mathrm{SPE}}\right)}{Q_{\mathrm{a}}}\right\}=\frac{\left(1-\frac{T_{o}}{T_{\mathrm{H}}}\right)}{\left(1-\frac{T_{o}}{T_{\text {adia }}}\right)}
$$

$Q_{\text {SPE }}$ is based on Carnot work which is defined at application temperatures. Whereas $Q_{a}$ is the actual energy supplied at bled steam temperature. Since the steam inlet temperatures to different thermally driven desalination processes are different, hence the $\mathrm{CF}_{\text {thermal }}$ are determined separately for assorted plants.

Using the physically meaningful conversion factors, namely $\mathrm{CF}_{\text {elec }}$ and $\mathrm{CF}_{\text {th }}$, these factors transform the absolute values (quantity and quality) of derived energy consumed by diverse desalination methods to the common platform primary energy consumption, enabling a cross comparison of energy efficiency from all desalination methods. In brief, the thermodynamic framework provides the common energy platform that served two key roles: Firstly, the fractional apportionment of standardized primary energy consumption, conducted on the cascaded processes of CCGT to the respective electricity, low-grade thermal sources, etc., yielded the causal calibrated conversion factors for the derived energy to power all diverse processes in industry. This calibration of conversion factors is performed with the best power plant systems available hitherto. Secondly, the calibrated conversion factors enable the conversion of specific energy consumption of practical desalination plants, consuming either electricity or thermal sources, into a common energy platform of $Q_{\text {SPE }}$. The relative consumption of standardized $Q_{\text {SPE }}$ for water produced from all types desalination methods can now be compared accurately.

In conclusion, the common energy temperature platform has been used to evaluate and compare the consumption of standard primary energy $\left(Q_{\mathrm{SPE}}\right)$ by assorted seawater desalination methods. In cogenerating electricity and thermal heat sources from the best conversion plant available hitherto, the apportionment of respective $Q_{\text {SPE }}$ to the derived energy at a common platform embeds their absolute quantity and quality of input fossil fuels. Based on the thermodynamic framework presented here, the causal conversion factors $\left(\mathrm{CF}_{\text {elec }}\right.$ and $\left.\mathrm{CF}_{\text {th }}\right)$ are devised, enabling the direct conversion of $\mathrm{kWh}_{\text {elec }}$ or $\mathrm{kWh}_{\mathrm{th}}$ into the common energy platform of $Q_{S P E}:-$ An essential requisite needed for a just comparison of energy efficiency of multifarious desalination processes or methods.

Since 1983 till now, the energy efficiency of SWRO methods were shown to be better than thermally driven methods of MSF and MED. Comprehensively, all existing desalination methods were relatively energy inefficient, at specific energy efficiencies spanning between 7 and $16 \%$ of the thermodynamic limit of $1.06 \mathrm{~m}^{3} / \mathrm{kWh}$ SPE. Recent hybrid designs of thermally driven processes have improved significantly with the twofold increase in energy efficiency, from $<10 \%$ to about $20 \%$. The increase in energy efficiency is observed at a common energy platform $\left(Q_{\mathrm{SPE}}\right)$ where the better utilization of thermal energy have synergistically minimized dissipative losses within the cascaded processes. For example, the HT-MED-TVC (Doosan/SWCC at Yanbu, SA), the MSF + RO plant (Ras Al Khair, SA), the MEDAD (KAUST, SA) and the multi-stage DCSEC (KAUST, SA) have all incorporated the extension of operational thermal boundary limits, either at the top-brine (better control of scaling) or the low-brine temperatures (avoided the ambient limit in MED stages by the sorption uptake of vapor by re-generated adsorbent), as well as the better heat recovery in the condensers of DCSEC. Despite only laboratory pilot tests, the increasing trend of thermally driven desalination methods predicts that a higher target for energy efficiency of future seawater desalination methods could reach up to $30 \%$ of the ideal limit. It is opined that such a projection is both realistic and tenable for achieving sustainable seawater desalination. Concurrently, a similar break-through in the near future in the work-driven alternatives (membranes and hybrid $\mathrm{PRO}^{68,69}, \mathrm{MCD}^{70}$, etc) is plausible with the relentless pursuit for improved membrane sciences and materials.

\section{DATA AVAILABILITY}

The data that support the analysis and findings of this study is available as supplementary table and additional data will be available from the corresponding author upon request.

Received: 22 May 2020; Accepted: 8 March 2021; Published online: 08 April 2021 


\section{REFERENCES}

1. Kummu, M. et al. The world's road to water scarcity: shortage and stress in the 20th century and pathways towards sustainability. Sci. Rep. 6, 38495 (2016).

2. Rockström, J. et al. A safe operating space for humanity. Nature 461, 472-475 (2009).

3. Shahzad, M. W., Burhan, M., Ang, L. \& Ng, K. C. Energy-water-environment nexus underpinning future desalination sustainability. Desalination 413, 52-64 (2017).

4. Market insight: Global water market 2018. Global Water Intelligence Report, https://www.globalwaterintel.com/products-and-services/market-researchreports/global-water-market-2018 (2018).

5. Charcosset, C. A review of membrane processes and renewable energies for desalination. Desalination 245, 214-231 (2009).

6. Shatat, M. \& Riffat, S. B. Water desalination technologies utilizing conventional and renewable energy sources. Int. J. Low. Carbon Tech. 9, 1-19 (2014).

7. Boretti, A. et al. Outlook for graphene-based desalination membranes. NPJ Clean Water 1, 5 (2018).

8. Shahzad, M. W. et al. Desalination processes efficiency and future roadmap. Entropy 21-1, 84 (2019).

9. Caton, J. A. The thermodynamics of internal combustion engines: examples of insights. Inventions 3, 33 (2018)

10. Senft, J. R. Mechanical Efficiency of Heat Engines (Cambridge Univ. Press, 2007).

11. GE's HA Gas Turbine Delivers Second World Record for Efficiency (https://www. ge.com/news/press-releases/ges-ha-gas-turbine-delivers-second-world-recordefficiency, accessed 15-July-2020).

12. Mistry, K. H. \& Lienhard, J. H. Generalized least energy of separation for desalination and other chemical separation processes. Entropy 15-6, 2046-2080 (2013)

13. Ham, F. V. D. Eutectic Freeze Crystallization. (Technische Universiteit Delft, 1999) (Eutectic Freeze-TU Delft Repositories, repository.tudelft.nl).

14. Hamed, O. A. Fuel utilization of steam power cycles integrated with multi stage flash (MSF) desalination plants. Desalination Water Treat. 140, 7-13 (2019).

15. Hamed, O. A. et al. Thermoeconomic analysis of a power/water cogeneration plant. Energy 31-14, 2699-2709 (2006).

16. Benson, R. S. (1st eds) The thermodynamics and gas dynamics of internalcombustion engines (Cambridge Univ. Press, 1982).

17. Gordon, M. J. \& Ng, K. C. Cool Thermodynamics (Cambridge International Science Publishing Ltd, 2000).

18. Spiegler, K. S. \& El-Sayed, Y. M. The energetics of desalination processes. Desalination 134, 109-128 (2001).

19. Alasfour, F., Darwish, M. \& Amer, A. B. Thermal analysis of ME-TVC + MEE desalination systems. Desalination 174, 39-61 (2005).

20. Kahraman, N. \& Cengel, Y. A. Exergy analysis of a MSF distillation plant. Energy Convers. Manag. 46, 2625-2636 (2005).

21. Veza, J. M. Mechanical vapour compression desalination plants-A case study. Desalination 101, 1-10 (1995).

22. Cerci, Y. Exergy analysis of a reverse osmosis desalination plant in California. Desalination 142, 257-266 (2002)

23. Fitzsimons, L. et al. Exergy analysis of water purification and desalination: a study of exergy model approaches. Desalination 359, 212-224 (2015).

24. Mabrouk, A. N. \& Fath, H. E. S. Technoeconomic study of a novel integrated thermal MSF-MED desalination technology. Desalination 371, 115-125 (2015).

25. Ghaffour, N., Missimer, T. M. \& Amy, G. Technical review and evaluation of the economics of water desalination: current and future challenges for better water supply sustainability. Desalination 309, 197-207 (2013).

26. Patel, S. K. et al. The relative insignificance of advanced materials in enhancing the energy efficiency of desalination technologies. Energy Environ. Sci. 13, 1694-1710 (2020).

27. Hummer, G., Rasaiah, J. C. \& Noworyta, J. P. Water conduction through the hydrophobic channel of a carbon nanotube. Nature 414, 188-190 (2001)

28. Holt, J. K. et al. Fast mass transport through sub-2-nanometer carbon nanotubes. Science 312, 1034-1037 (2006).

29. Pendergast, M. T. M. \& Hoek, E. M. V. A review of water treatment membrane nanotechnologies. Energy Environ. Sci. 4, 1946-1971 (2011).

30. Agre, P., Sasaki, S. \& Chrispeels, M. J. Aquaporins: a family of water channel proteins. Am. J. Physiol.-Ren. Physiol. 265, 265-270 (1993).

31. Li, N. N. et al. Advanced Membrane Technology and Applications (John Wiley \& Sons, Inc. 2008).

32. Wang, J. et al. A critical review of transport through osmotic membranes. J. Membr. Sci. 454, 516-537 (2014).

33. $\mathrm{Wu}, \mathrm{J}$. J. On the application of the Spiegler-Kedem model to forward osmosis. BMC Chem. Eng. 1, 15 (2019).

34. Mohammadi, K. et al. Hybrid concentrated solar power (CSP)-desalination sys tems: a review. Desalination 468, 1140823 (2019).

35. Palenzuela, P. et al. Concentrating Solar Power and Desalination Plants (Springer International Publishing, 2015).
36. European Commission Horizon 2020 grant call. Efficient combination of Concentrated Solar Power and desalination (with particular focus on the Gulf Cooperation Council (GCC) region), Call ID: H2020-LC-SC3-2018-2019-2020 (https://ec. europa.eu/info/funding-tenders/opportunities/portal/screen/opportunities/topicdetails/lc-sc3-res-20-2020, accessed 10-July-2020).

37. The U.S. Department of Energy (DOE) Solar Desalination Prize (https:// americanmadechallenges.org/solardesalination/, accessed 10-July-2020).

38. NREL \$9 Million Solar Desalination Prize Competition (2020). (https://www.nrel. gov/news/program/2020/nrel-launches-9-million-solar-desalination-prizecompetition.html, accessed 10-July-2020).

39. Lahn, G., Stevens, P. \& Preston, F. Saving Oil and Gas in the Gulf. A Chatham House Report (2013) (https://www.chathamhouse.org/sites/default/files/public/Research/ Energy\%2C\%20Environment\%20and\%20Development/0813r_gulfoilandgas.pdf, accessed 25-June-2020)

40. Shahzad, M. W., Burhan, M. \& Ng, K. C. A standard primary energy approach for comparing desalination processes. NPJ Clean. Water 1, 1-7 (2019).

41. Chen, $L$. et al. Minimum energy requirement of an endoreversible desalination system of sea water. Int. J. Energy Environ. Eng. 6-4, 331 (2015).

42. Lavenda, B. H. The thermodynamics of endoreversible engines. Am. J. Phys. 75 169 (2007).

43. Masser, R. \& Hoffmann, K. H. Dissipative endoreversible engine with given efficiency. Entropy 21, 1117 (2019).

44. Muschik, W. \& Hoffmann, K. H. Endoreversible thermodynamics: a tool for simulating and comparing processes of discrete systems. J. Non-Equilib. Thermodyn. 31, 293-317 (2006)

45. Ng, K. C. et al. An exergy approach to efficiency evaluation of desalination. Appl. Phys. Lett. 110, 184101 (2017).

46. Sanz, M. A. Energy as Motor of Seawater Reverse Osmosis Desalination Development (WEX, 2012)

47. Al-Shammiri, M. \& Safar, M. Multi-effect distillation plants: state of the art Desalination 126, 45-59 (1999).

48. Tonner, J. Barriers to thermal desalination in the United States, Desalination and water purification research and development program report (US Department of the Interior, 2008).

49. Economic and Social Commission for West Asia. Water desalination technologies in the ESCWA member countries (ESCWA, UN, 2001).

50. Wade, N. M. Distillation plant development and cost update. Desalination 136 3-12 (2001).

51. Borsani, R. \& Rebagliati, S. Fundamentals and costing of MSF desalination plants and comparison with other technologies. Desalination 182, 29-37 (2005).

52. Blank, J. E., Tusel, G. F. \& Nisanc, S. The real cost of desalted water and how to reduce it further. Desalination 205, 298-311 (2007).

53. IRENA. Water Desalination Using Renewable Energy, IEA-ETSAP and IRENA Technology Brief 112 (IRENA, 2012).

54. Ihm, S. et al. Energy cost comparison between MSF, MED and SWRO: case studies for dual purpose plants. Desalination 397, 116-125 (2016).

55. Farooque, A. M. et al. Parametric analyses of energy consumption and losses in SWCC SWRO plants utilizing energy recovery devices. Desalination 219, 137-159 (2008).

56. Lemes, R. et al. Evolution of Production and Energy Savings in SWRO Plant of Las Palmas III. IDA World Congress-2011 REF: PER11-230 (2011).

57. Lee, Y. et al. High temperature ( 85 C) MED technology development. (http://www sawea.org/pdf/2017/18th_Oct/younggeun Lee.pdf, assessed 10-July 2020)

58. Shahzad, M. W. \& Ng, K. C. On the road to water sustainability in the gulf, nature middle east, https://doi.org/10.1038/nmiddleeast.2016.50 (2016).

59. Shahzad, M. W., Ng, K. C. \& Thu, K. Future sustainable desalination using waste heat kudos to thermodynamic synergy. Environ. Sci.: Water Res. Technol. 2, 206-212 (2016).

60. Thu, K. et al. Performance investigation of an advanced multi-effect adsorption desalination (MEAD) cycle. Appl. Energy 159, 469-477 (2015).

61. Shahzad, M. W., Thu, K., Kim, Y. D. \& Ng, K. C. An experimental investigation on MEDAD hybrid desalination cycle. Appl. Energy 148, 273-281 (2015).

62. $\mathrm{Ng}, \mathrm{K}$. C. et al. Recent developments in thermally-driven seawater desalination: energy efficiency improvement by hybridization of the MED and AD cycles. Desalination 356, 255-270 (2015).

63. Shahzad, M. W. et al. Multi effect desalination and adsorption desalination (MEDAD): a hybrid desalination method. Appl. Therm. Eng. 72, 289-297 (2014).

64. Son, H. S. et al. Pilot studies on synergetic impacts of energy utilization in hybrid desalination system: multi-effect distillation and adsorption cycle (MED-AD). Desalination 477, 114266 (2020).

65. AlRowais, R. et al. A greener seawater desalination method by direct-contact spray evaporation and condensation (DCSEC): experiments. Appl. Therm. Eng. 179, 115629 (2020)

66. Chen, $Q$. et al. A self-sustainable solar desalination system using direct spray technology. Energy 205, 118037 (2020). 
67. Wu, J. J. \& Field, R. W. On the understanding and feasibility of "Breakthrough" Osmosis. Sci. Rep. 9, 16464 (2019).

68. Childress, A. E. Latest Technology in Water Desalination, $1^{\text {st }}$ Arab-American Frontiers Symposium, Kuwait Institute for Scientific Research (KISR) and U.S. National Academies, October 17-19, 2011, Kuwait. https://sites.nationalacademies.org/cs/ groups/pgasite/documents/webpage/pga_066431.pdf

69. Kurihara, M. \& Takeuchi, H. SWRO-PRO System in "Mega-ton Water System" for energy reduction and low environmental impact. Water 10, 48-63 (2018).

70. Porada, S. et al. Review on the science and technology of water desalination by capacitive deionization. Prog. Mater. Sci. 58, 1388-1442.

71. Shahzad, M. W. et al. An innovative pressure swing adsorption cycle. AIP Conference Proceedings, 2062, 020057 (2019).

\section{ACKNOWLEDGEMENTS}

Authors would like to thank KAUST for the generous funding of the research and Northumbria University, UK for their research contributions. R.W.F. has been partially supported by an APEX award on Exploring Water Re-use-the Nexus of Politics, Technology and Economics from the Royal Society and British Academy with funding from the Leverhulme Trust.

\section{AUTHOR CONTRIBUTIONS}

K.C.N. proposed the idea, developed the methodology, and drafted the initial manuscript. M.W.S. developed a model and collected existing performance data of all desalination methods. They conducted CCGT and desalination cycle analysis and edited the final manuscript. M.B., C.Q., D.Y., and A.F. conducted experiments on the MEDAD pilot plant and the measured data is presented here. R.W.F. contributed to the interpretation of the results, further knowledge of membrane processes and furnished valuable suggestions on manuscript preparation. M.K. provided his expert advice during revision and thermodynamic modeling process.

\section{COMPETING INTERESTS}

The authors declare no competing interests.

\section{ADDITIONAL INFORMATION}

Supplementary information The online version contains supplementary material available at https://doi.org/10.1038/s41545-021-00114-5.

Correspondence and requests for materials should be addressed to M.W.S.

Reprints and permission information is available at http://www.nature.com/reprints

Publisher's note Springer Nature remains neutral with regard to jurisdictional claims in published maps and institutional affiliations.

(i) Open Access This article is licensed under a Creative Commons Attribution 4.0 International License, which permits use, sharing, adaptation, distribution and reproduction in any medium or format, as long as you give appropriate credit to the original author(s) and the source, provide a link to the Creative Commons license, and indicate if changes were made. The images or other third party material in this article are included in the article's Creative Commons license, unless indicated otherwise in a credit line to the material. If material is not included in the article's Creative Commons license and your intended use is not permitted by statutory regulation or exceeds the permitted use, you will need to obtain permission directly from the copyright holder. To view a copy of this license, visit http://creativecommons. org/licenses/by/4.0/

(c) The Author(s) 2021, corrected publication 2021 